\title{
Educational initiative of Osaka University in sustainability science: mobilizing science and technology towards sustainability
}

\author{
Michinori Uwasu · Helmut Yabar · Keishiro Hara • \\ Yoshiyuki Shimoda $\cdot$ Tatsuyoshi Saijo
}

Received: 30 September 2008/Accepted: 22 December 2008/Published online: 5 March 2009

(C) Integrated Research System for Sustainability Science and Springer 2009

\begin{abstract}
One of the most important and yet difficult challenges that modern societies face is how to mobilize science and technology (S\&T) to minimize the impact of human activities on the Earth's life support systems. As the establishment of inter-disciplinary education programs is necessary to design a unified vision towards understanding the complexity of human nature, the Research Institute for Sustainability Science (RISS) launched a new program on sustainability science in April 2008. The program expects to address the issue of how to use knowledge more effectively to understand the dynamic interactions between nature and human society. This paper first offers an overview of international and Japanese initiatives on sustainability education in which we highlight the uniqueness of the attempt by the Integrated Research System for Sustainability Science (IR3S). The paper then introduces the RISS program for sustainability science, addressing the principles and curriculum design of the program. The paper discusses the main problems and constraints faced when developing the program, such as institutional barriers in building a curriculum and obtaining cooperation from faculty. To challenge these barriers and limitations, the RISS uses the
\end{abstract}

M. Uwasu ( $₫) \cdot$ H. Yabar · K. Hara

Research Institute for Sustainability Science,

Osaka University, 2-1 Yamada-oka, Suita,

Osaka 565-0871, Japan

e-mail: uwasu@riss.osaka-u.ac.jp

Y. Shimoda

Division of Sustainable Energy and Environmental Engineering,

Osaka University, Osaka, Japan

T. Saijo

Institute of Social and Economic Research,

Osaka University, Osaka, Japan program as a platform to disseminate the idea of sustainability science across the university. This attempt helps us to obtain the continuing cooperation necessary to improve and maintain the program.

Keywords Sustainability science .

Sustainability education - Curriculum design .

Education network

\section{Introduction}

Most of the problems arising from the impact of human activities on the Earth's life support systems come from complex, global, and social human interactions. Unless we understand these interactions, we will not be able to design a path towards sustainable development. Sustainability science plays a key role in this understanding. Sustainability science is partly defined as "the comprehensive study on the multiple and complex interactions of the human, social, and global systems with the aim to achieve sustainable human well-being and societal development" (Komiyama and Takeuchi 2006). In order to address the sustainability challenge, Osaka University launched a new trans-disciplinary research organization, the Research Institute for Sustainability Science (RISS), in April 2006. The RISS introduced an integral and dynamic innovation system where science and technology (S\&T) play a key role in fulfilling societal functions (Morioka et al. 2006). As sustainability science provides the appropriate tools in the pursuit of an integral innovation system, the RISS established a new educational program in this field in April 2008.

Our program addressed the issue of how to use knowledge more effectively to understand the dynamic 
interactions between nature and human society. Universities have the potential to be niches where education for sustainable development (ESD) and sustainable practices are encouraged and disseminated. Most of the universities' courses relevant to sustainability seemingly focus on environmental issues. However, the RISS program aimed at providing students with integrated approaches and systematic analysis for sustainable development.

This paper first explores the history of sustainability education since its inception, including the main international initiatives, such as the United Nations Decade of Education for Sustainable Development (UNDESD), the North America University network, association of university leaders for a sustainable future, and the European network, Copernicus-Campus. We argue that these initiatives could have increased the awareness of sustainability in higher education around the world. In Japan, there are many programs relevant to sustainability that focus on environmental issues in the context of engineering and environmental science. Although the trend in Japan contrasts that in Europe and North America, where sustainability programs in social sciences are more popular, we highlight the Integrated Research System for Sustainability Science (IR3S) for the uniqueness and innovativeness of their approach and network among participating universities.

We then introduce the RISS educational program in sustainability science at Osaka University. The RISS program offers a minor certificate in sustainability science, open to all graduate students at Osaka University. The principles and scope of the program are based on the definition of sustainability science by the IR3S. We also show the curriculum design and the skills development framework. The program offers four core courses of sustainability science that provide holistic knowledge of sustainability, as well as key concepts, such as life-cycle and trade-off thinking, and covers a wide range of theories and issues related to sustainability through associate courses. The paper also places emphasis on the main problems and constraints that the RISS faces while developing the program. While there are critical institutional barriers and issues in faculty development in improving the program, we use sustainability education as a platform on which faculty and students have opportunities to understand the concept of sustainability science and contribute to its development.

\section{International and Japanese initiatives on sustainability education}

The role and importance of education as a tool to achieve sustainable development was stressed in the Agenda 21 program of the 1992 United Nations Conference on Environment and Development, known as the Earth Summit. Chapter 36 of Agenda 21 emphasized the importance of education, training, and public awareness towards sustainable societies (UNCED 1992). Four areas were highlighted in this program: quality of basic education, education programs toward sustainable development, public awareness and understanding, and training promotion. While all countries acknowledged the importance of ESD, little was done in the following years to promote and enhance this initiative, mainly as a result of the lack of leadership within the UN. This UN idea has been followed by specific initiatives of sustainability education in the context of developing countries and in higher education in developed countries.

International initiatives on sustainability education

\section{United Nations Decade of Education for Sustainable Development}

The 2002 World Summit on Sustainable Development (WSSD) emphasized the educational objectives of the Millennium Development Goals. The Summit also proposed the Decade of Education for Sustainable Development for the period 2005-2014 with UNESCO as the leading agency. The goal of ESD is to integrate the principles, values, and practices of sustainable development into all aspects of education and learning. In this sense, UNESCO argues that ESD should have the following characteristics: be inter-disciplinary and holistic, valuesdriven, have a critical thinking and problem-solving approach, include multi-methods for teaching, and be participation-oriented and locally relevant. The UN is committed to disseminate ESD by promoting an increased quality in teaching and learning, facilitating interaction, exchange, and networking among stakeholders, and providing countries with new opportunities to incorporate ESD into their education reforms.

During the 2002 WSSD, the world-leading educational and scientific organizations signed the Ubuntu Declaration on education and S\&T for sustainable development. The main goals of the Ubuntu Declaration are (UNU-IAS 2005):

- Strengthening of collaboration between educators and S\&T researchers

- Better integration of S\&T into educational programs for sustainable development at all levels

- Problem-based approach for education and scientific research

- Innovation in knowledge transfer to bridge the gaps and inequalities in knowledge. 
The Association of University Leaders for a Sustainable Future

The Association of University Leaders for a Sustainable Future (ULSF) started from the Talloires Declaration, which was an agreement in 1990 at the international conference on "The Role of Universities in Environmental Management and Sustainable Development," held in Talloires, France. This declaration was the first official statement made by university administrators of a commitment to sustainability in higher education (Calder and Clugston 2003). The mission of the ULSF is to support sustainability as a critical focus of teaching, research, operations, and outreach at colleges and universities worldwide through publications, research, and assessment.

\section{Copernicus-Campus}

Copernicus-Campus is the university network for sustainability in Europe. More than 300 European universities from 38 countries are members of this network. Copernicus-Campus focuses on the activities of higher education institutions related to sustainable development and aims to balance economic, environmental, and socio-cultural aspects in the institutional management of curricula and services to the local/regional community (Copernicus Campus Sustainability Center 2006). The network developed a university charter that encourages all of its members to give sustainable development an important role in all their activities.

Japanese initiatives on sustainability education

As we saw in the previous sub-section, there have been many international initiatives promoting sustainability in higher education. The results of these efforts are still unclear. Some studies, such as Wright (2004), assert that many initiatives trying to promote the sustainability concept in higher education have had little impact on education. Perhaps the most important outcome of these initiatives is that everybody now recognizes the need to include the sustainability concept at all levels of education. In this sense, the Japanese government strategy aims at the future direction of sustainability education in Asia.

\section{Sustainability education in the context of Japanese policy}

The Japanese government formulated its plan Becoming a Leading Environmental Nation Strategy in the 21st Century-Japan's Strategy for a Sustainable Society in June 2007. The strategy proposes to build a sustainable society through comprehensive measures integrating the following three aspects of the society: (1) a low-carbon society,
(2) a sound material-cycle society, and (3) a society in harmony with nature (Government of Japan 2007). Eight strategies with priority in the next 1-2 years are presented in the 21 st century environmental nation strategy. One of them is the better provision of education to the public. The main strategy is to create diverse opportunities for environmental education and learning for a wide range of participants and to launch initiatives to train international educational leaders in Asia.

Following the plan above and some other policy movements, the Japanese government drafted Environmental Leadership Initiatives for Asian Sustainability in 2008, in recognition of the importance of education. Under the initiative, the Ministry of Environment of Japan plans to support and proceed with the following projects: (1) development of model programs at colleges and graduate schools, (2) development of a consortium through the partnership of industry, government, and the public, and (3) development and strengthening of networks among the universities in Asia.

\section{Sustainability in higher education in Japan}

In Japan, there are numerous graduate programs in the sustainability field, such as environmental management, resource circulation and energy, social systems, and risk communications. ${ }^{1}$ While emphasizing the importance of an inter-disciplinarity, most of the programs are established within the fields of engineering and environmental science. This observation contrasts with international initiatives on sustainability, which put more focus on social development and quality of life. In fact, in Europe and North America, many sustainability programs are found in the field of social sciences, such as economics, political science, and business/management (Banas 2007).

The IR3S attempts to establish graduate programs for sustainability science at the master's level in the five participating universities. ${ }^{2}$ The uniqueness of the attempt by the IR3S is that these programs are the first comprehensive programs that integrate different academic disciplines and education networks in sustainability science in Japan. As the IR3S defines, sustainability science is "a new academic discipline that seeks to understand the interactions within

\footnotetext{
1 This observation is based on our own research through the Internet, as official information was not available.

2 The IR3S, started in April 2005, is a 5-year project funded by the Ministry of Education, Culture, Sports, Science and Technology (MEXT) of Japan. The mission of the IR3S is to establish sustainability science by promoting activities in three fields; research, education, and cooperation with industries in sustainability. The University of Tokyo is the main bronchus and Hokkaido University, Kyoto University, Ibaraki University, and Osaka University are the participating universities.
} 
and between global, social, and human systems, the complex mechanisms that lead to degradation of these systems, and concomitant risks to human well-being and security, and then to propose visions and methods for repairing these systems and linkages." This definition requires us to employ a trans-disciplinary approach in curricula and to focus on practical training for sustainability issues. Also, given that sustainability deals with such vast research areas, the IR3S is aware that building a network among the participating universities is not only essential to meet these requirements, but is also a means to maximize the capacity of the universities.

\section{The RISS program, Osaka University}

Osaka University was established in 1931 as the sixth imperial university, located in the western part of Japan. It is a large organization consisting of 11 schools with ten corresponding graduate schools and with more than 8,000 faculty and staff and 25,000 students. Osaka University has long been strong in the fields of engineering and natural science, devising a number of new scientific technologies related to the environmental and energy fields. Yet, at the same time, Osaka University has realized the difficulty of improving mature technology and conducting system reorganization simply by relying on individual technology developments that are applications of advanced pure science. The RISS was, therefore, established in April 2006 as the institutional branch of the IR3S at Osaka University, to mobilize S\&T to minimize the impact of human activities on the Earth's life support systems.

\section{Introduction to the RISS Program}

In April 2008, the RISS launched a new graduate educational program in Osaka University ${ }^{4}$ as a flagship project of the IR3S to contribute to the establishment of a new academic discipline-sustainability science. At Osaka University, the RISS is intended to offer a minor program in sustainability science in which eight credits are necessary to complete and any students enrolling in the master's program at Osaka University are eligible for the program.

The mission of the RISS program stands on the IR3S' definition of sustainability science. Specifically, the aim is to nurture students who:

\footnotetext{
3 http://www.ir3s.u-tokyo.ac.jp/en/index.html.

${ }^{4}$ We offered two pilot core courses of sustainability science in the fall semester of 2007 in the Schools of Engineering and Economics, respectively. These courses can be included for the current program's requirements. Thus, technically speaking, the RISS program started in this semester.
}

- Understand the interactions within and between global, social, and human systems, the complex mechanisms that lead to the degradation of these systems, and concomitant risks to human well-being and security

- Are able to propose visions and methods for protecting and/or restoring these systems and linkages.

We believe that mobilizing S\&T among all people in Osaka University is essential to the attainment of our mission. One of the reflections to this is to provide students from different academic backgrounds with opportunities to deliberate sustainability issues from a variety of perspectives through the education program. The program also attempts to maintain the diversity of instructors in the academic fields in the curriculum. These reflections help us disseminate the idea of sustainability science among Osaka University's faculty members, as well as students.

The objective of our program is to improve students' sustainability literacy. In pursuit of sustainability, it is imperative to first comprehend the complex relationship between the human system, such as life-style and human activities, and socio-economic systems, such as institutions and global environmental systems. It is important for students to obtain 'sustainability literacy' to deal with sustainability and, thus, providing such literacy in the classroom is among the crucial missions of sustainability education offered by the RISS.

Sustainability literacy in general can refer to the knowledge and skills necessary to contribute to a more sustainable society (Stibbe 2008) and, thus, we have our own definition. Sustainability literacy is defined by, apart from the basic and essential knowledge about sustainability and the environment, the ability to systematize the complexity of global sustainability, the capability to come up with the best available option or solution, even under the condition of uncertainty and trade-off, which we might encounter very often in coping with sustainability, and a systematic approach to tackle the complicated issues. In addition, particularly when it comes to dealing with global environmental issues, it is probable that cooperation will be needed beyond the boundary of disciplines, cultures, and countries. This means that the capacity to accept the diversities in the background of disciplines, cultures, and religions is indispensable. By the end of the program, students will be able to maximize the effectiveness of their knowledge and skills in their major academic major field, collaborating with others from different backgrounds, to solve sustainability issues.

\section{Curriculum design}

The curriculum design should reflect our mission and educational philosophy. In this regard, it is of critical 
importance to provide such opportunities as interactive discussions among the students by providing some specific themes relating to sustainability, along with the regular lectures. This gives students the opportunities to learn how to solve issues with a flexible mind, using a trans-disciplinary approach and international awareness, while accommodating the diversities of others.

As of the academic year 2008, the RISS program consists of 12 courses, including four sustainability core courses (elective required) and eight sustainability associate courses (elective). These 12 courses are offered through various departments/schools at Osaka University, covering a wide range of academic disciplines and approaches. Table 1 lists the course names and schools and provides the scope of each course in the RISS curriculum. The program completion requirements are as follows. First, students should complete eight credits (four courses) in total from the curriculum courses. Second, out of the eight credits, four credits (two courses) should be taken from the core courses. Third, students need to meet their master's program requirements. The program certificate is issued under the name of the presidents of Osaka University and the RISS.

\section{Core courses (elective required)}

The RISS offers four core courses for sustainability science. The core courses are intended to provide students with opportunities to learn skills and different perspectives essential to understanding the interactive mechanisms within and between the global, social, and human systems. Through specific examples, students will obtain holistic knowledge of sustainability issues such as global warming and energy, food, and water issues. Students will also learn the use of tools such as life-cycle assessment and the importance of trade-offs between different dimensions (economy vs. environmental quality, inter-generations, and so on), as well as the role of uncertainty and dynamics. In addition, students will learn not only the limitations but also the usefulness of existing theories and practices, so that they will be able to select and integrate those approaches to challenge sustainability issues. In this sense, sustainability science is trans-disciplinary in that these core courses challenge questions that cross disciplines (Lattuca 2001). Table 2 provides brief descriptions of the sustainability core courses.

The core courses comprise lectures that are primarily provided by faculty members of Osaka University and the IR3S universities, in addition to group discussions, projects, and field trips. The group discussion and projects in the core courses are based on problem-based learning (Martens 2007). Specifically, students discuss issues in sustainability from different perspectives, such as the use of biomass energy, water management, knowledge structuring of sustainability, and urban design for low carbon emissions. These activities are intended to: (1) integrate the theories, (2) bridge the gap between the theories and practices, and (3) develop students'

Table 1 Courses in the Research Institute for Sustainability Science (RISS) program

\begin{tabular}{lll}
\hline Course name & Scope & Offered at the School of ... \\
\hline $\begin{array}{l}\text { Sustainability core courses (elective required) } \\
\text { Economics of global warming }\end{array}$ & Sustainability science (trans-discipline) & Economics \\
$\begin{array}{l}\text { Valuation methods and technology for } \\
\text { sustainability }\end{array}$ & Sustainability science (trans-discipline) & Engineering \\
Global threats and sustainability (offered in & Sustainability science (trans-discipline) & Communication design center \\
2007 and 2009) & & Human science \\
Society and the environment: human security & Integration of human and social sciences & Engineering \\
and sustainability & & \\
Engineering system design for sustainability & Integration of engineering (environmental & Human science \\
& management, civil engineering, and mechanical & Law \\
Sustainability associate courses (elective) & engineering) & International public policy \\
Environmental psychology & Human system & Engineering \\
Environmental law & Social system & Engineering \\
Economic development and the environment & Social and human systems & Engineering \\
Bio-engineering & Global system & Communication design center \\
Energy demand systems & Human and global systems & Science and engineering science \\
Urban design & Human and social systems & Communication skills \\
Science and technology communications & Global system, ethical attitude &
\end{tabular}


Table 2 Brief description of the core courses in the RISS program

\begin{tabular}{lc}
\hline Course name & Objective \\
\hline $\begin{array}{l}\text { Valuation methods and technology for } \\
\text { sustainability }\end{array}$ & $\begin{array}{c}\text { This course introduces students to a broad range of valuation methods and technologies in } \\
\text { sustainability. Students are expected to understand, through specific examples, the usefulness as } \\
\text { well as the limitations of existing theories and to apply them to the real sustainability issues }\end{array}$ \\
$\begin{array}{c}\text { Global threats and sustainability (canceled } \\
\text { in 2008) }\end{array}$ & $\begin{array}{c}\text { This course examines both causes and consequences of environmental and social change, which } \\
\text { provides students with an idea of why a trans-disciplinary approach is necessary in } \\
\text { sustainability. It also deals with specific issues in the environment that are of particular } \\
\text { importance in the Asian region, such as energy, food/water, overuse of natural resources, and } \\
\text { population growth } \\
\text { This course introduces issues relevant to human security and the environment around the world. It } \\
\text { is intended to equip students with the ability of problem finding in the area, as well as the } \\
\text { solutions to them by understanding the interactions between the social and global systems } \\
\text { security and sustainability }\end{array}$ \\
$\begin{array}{c}\text { This course deals with the theories of three research fields in engineering; environmental } \\
\text { mangineering system design for sustainability }\end{array}$ \\
group projects by proposing solutions to a specific sustainability issue
\end{tabular}

communication and practical skills for challenging sustainability issues.

\section{Sustainability associate courses (elective)}

Sustainability associate courses deal with topics related to sustainability. The current associate courses had already existed in the ordinary master's curricula before our program started. We first investigated the contents of most courses in the master's program at Osaka University and selected potential courses for associate courses. We then contacted instructors to ask them if their courses could also be credited as a sustainability associate course in the RISS program.

The selection criteria for the sustainability associate courses are one or more of the following: (1) to deepen the knowledge of the global, human, and social systems, (2) to learn ethical attitudes of scientists and engineers, (3) to deal with useful skills for sustainability practices. The courses selected according to the first criterion include: Environmental Psychology, Environmental Law, Economics and the Environment, Urban Design, Energy Demand Systems, and Bio-engineering. The courses selected according to the second and third criteria are Science and Technology, and Science and Technology Communications.

Outline of the RISS program and educational activities

Table 3 presents the number of enrolled students and their composition. As of the spring semester of 2008, 22 students are enrolled on our program. These students are from four different schools: Engineering, Engineering Science, Economics, and Human Science. Among the 22 enrolled students, 17 students are from the School of Engineering, but belong to different departments, including Environment
Table 3 Composition of students

\begin{tabular}{lc}
\hline & Spring semester 2008 \\
\hline Engineering & 17 \\
Engineering Science & 1 \\
Economics & 3 \\
Human Science & 1 \\
Total & 22 \\
\hline
\end{tabular}

and Sustainable Energy, Civil Engineering, Mechanical Engineering, Material Science, and Bio-engineering and Life Science. 5

Contents of the program courses and educational activities

In the core courses, exercise opportunities were offered to students in between the lectures, where students were given a specific issue within the theme. In Engineering System Design for Sustainability, one of the sustainability core courses offered in the spring semester of 2008, we conducted a team project "pursuing a sustainable city." With the knowledge and skills learnt in the class, students with different academic backgrounds discussed the technology or technology system for building a sustainable city and a low-carbon society, and formulated proposals consisting of technology systems which would contribute towards this goal. In Valuation Methods and Sustainability Technology, the other core course offered in fall 2007, we led a group project discussing the pros and cons about the use of biofuels. Students learnt engineering ontology as a tool for the knowledge structuring of sustainability through lectures and then they were given a task to apply the tool to the biofuels case as a group project. The use of such a tool and

\footnotetext{
5 The Graduate School of Engineering is the largest school at Osaka University, consisting of ten divisions.
} 
idea (knowledge structuring and engineering ontology) in a group work environment helps students understand the trade-off relationships between energy and food, as well as the significance of life-cycle thinking, and finding different views and ideas about the issue.

We also made a field trip to the Hyogo eco-industrial park located in the Kansai region, Japan, in the spring semester of 2008. Before the trip, students learned how the Hyogo eco-industrial park achieves $100 \%$ recycling by extracting carbon, gases, oils, and steel wires from waste tires and utilizing all of the materials and energy for their steel production. During the trip, students not only observed the recycling plant but were also able to exchange opinions with the plant officials. Through these activities, students had opportunities to absorb a variety of aspects for sustainability by sharing their viewpoints and tackle a common theme collectively. We found that this type of exercise was very effective in bringing students to a better understanding of multi-disciplinary studies.

Since the beginning of the RISS in April 2006, we have also organized several special seminars related to sustainability education, aiming at the outreach of sustainability education to faculty members as well as students at Osaka University. In February 2007, we held an international workshop for sustainability education, inviting prominent researchers and educators in the field, including Dr. R. Mckeown (University of Tennessee), Dr. P. Shi (Beijing Normal University), Dr. T. Mino (University of Tokyo), and Dr. T. Suzuki (Oxford University). In the spring semester of 2008, we invited Dr. Steinfeld (M.I.T.) to hold a series of workshops on sustainability education and green chemistry. These workshop seminars provided opportunities for the students as well as faculty to learn the current issues in the field of sustainability science and sustainability education.

\section{The Advanced Associate Program System}

The RISS program was built on the Advanced Associate Program System of Osaka University. The Advanced Associate Program is an unique system in higher education that Osaka University launched in April 2008. The establishment of the Advanced Associate Program reflects the current concerns of Osaka University. The recent development of new scientific research fields, such as nanotechnology, indicates the need for a different educational approach. It is necessary to learn skills and knowledge beyond the borders of academic disciplines. Also, it becomes more important to learn new topics that are not taught in the traditional courses, such as S\&T communications and ethical attitudes. While Osaka University traditionally has strong departments in the field of natural and medical sciences and engineering, it has weakness in interdisciplinary academic fields, such as environmental sciences.

Hence, the Advanced Associate Program System aims to equip students with broader knowledge and scope. As of 2008, 14 programs are operated as the Advanced Associate Program. Most of the programs deal with interdisciplinary research fields and topics. Examples of such programs include Nano-Science Technology, Environmental Risk Management, Communication Design, and Finance and Insurance.

The RISS determined to join the Advanced Associate Program System primarily because its principles match that of our program. Delivering broad aspects and knowledge within academic research fields fits well with the idea of sustainability science. Another reason is that building a program within the university's framework brings practical advantages. Officially, courses in our curriculum are offered thorough the departments that have a master's program. This limitation involves substantial bureaucratic work when we open new courses, but the backing of the university system helps us build new institutions, such as educational programs. Also, the university provides publicity services for our program.

\section{Discussion}

\section{Barriers and challenges at Osaka University}

Education programs such as the RISS program cannot be operated without the support of faculty members of the university. At Osaka University, the RISS is not a body that can open academic courses and, so, curriculum courses are offered through different schools. Also, RISS faculty members alone cannot cover such a variety of research fields in sustainability in the curriculum. These limitations mean that we need the regular involvement of faculty members from different schools at Osaka University. It is often difficult to receive constant support from them because most faculty members are busy with their ordinary duties and have little information about or interest in sustainability science.

From a student's point of view, these institutional limitations generate practical and psychological barriers. The credit system varies across programs and some departments do not account for credits from different schools. Also, for students majoring in the humanities, for example, registering courses in the engineering school would be a burden. Class locations across different campuses can also be a physical barrier for some students in scheduling class registration. Osaka University has two main campuses, which are located within a 30-min distance by a campus connector. In an attempt to reduce this burden, we have 
implemented a remote lecture system in the core courses connecting the two campuses. ${ }^{6}$

Toward the better program

The objective of the RISS is not only to disseminate the concepts of sustainability science within the university, but also to challenge the institutional limitations to obtain constant cooperation from faculty members at Osaka University. As an attempt, we have carried out informal interviews with faculty (both current and prospective instructors) and currently enrolled students: (1) to have them understand the RISS program and (2) to find out what they think about us as well as sustainability science. We interviewed 12 key faculty members from the Schools of Engineering, Engineering Science, Pharmaceutical Sciences, Economics, and the Communication Design Center, and 21 students who were enrolled in our program between April and July 2008. While there are possibly sample selection biases in their opinions and suggestions, the feedback is still valuable and interesting in helping to improve the RISS program.

From the interview with faculty, we found that most of them have a positive attitude towards the philosophy approaches of the RISS education program, although they have some negative opinions about sustainability science as an academic discipline. In particular, some faculty members pointed out that the core courses merely deliver the collection of different ideas in different views unless a core concept of sustainability science is shared among instructors.

The IR3S has reached a general consensus on sustainability core courses in that sustainability science programs should have courses that teach holistic knowledge about sustainability issues. Yet, there is a debate over what specifically to teach as an introduction to sustainability science. At the RISS, we are attempting to develop documented guidance for the core courses and share it with instructors and faculty. We also hold workshops and seminars to deliver findings and knowledge in sustainability science and sustainability education to faculty and students. In this sense, the RISS program can be the platform for faculty members in which new research and educational topics can be discussed.

From the students' point of view, we found that, in general, students have strong interests in environmental issues, regardless of their academic backgrounds. Yet, we saw some differences depending on their academic backgrounds. Some students majoring in natural sciences and engineering tend to have a strong motivation to delve into

\footnotetext{
6 There is another campus in Minoo near the two main campuses. Only the School of Foreign Studies is located in the campus.
}

their academic field in pursuing their master's curriculum, while others show interests in social sciences, such as economics. On the other hand, students majoring in social and human sciences seem to have less interest in other academic fields, particularly technology and engineering.

It is important to reduce any burden on students and to encourage them to participate in the RISS program. As the current program enrolment shows (Table 2), there are only four students in the program who are majoring in social and human sciences. Importantly, maintaining diversity in academic backgrounds in the program is crucial in terms of our educational philosophy. The RISS has two plans for this: (1) holding a program orientation of the RISS program in each department and (2) expanding sustainability associate courses in social and human sciences.

\section{Concluding remarks}

This paper has introduced the educational program for sustainability science at the Research Institute for Sustainability Science (RISS) and analyzed its approach to show how it is effective in responding to the increasing demand for the utilization of existing knowledge and technologies. The RISS program provides opportunities for students from all of the graduate schools at Osaka University to learn sustainability science by interacting with different academic and cultural backgrounds. Also, the RISS program plays an important role in disseminating the knowledge of science and technologies and, thus, can be the platform for sustainability science for faculty members at Osaka University to promote research activities in this field.

Yet, we are aware that Osaka University alone cannot accomplish the mission of sustainability education. There remained important themes and topics in sustainability science that are not dealt with in our curriculum. Therefore, to improve the program in cooperation with the Integrated Research System for Sustainability Science (IR3S) universities is of particular importance. The IR3S is working to build a network with three levels of activities:

1. The IR3S promotes the interchange of students and faculty across universities through the credit exchange system. At the time of writing of this paper, Osaka University is working to reach an agreement with Kyoto University for a credit exchange system. These two universities are located within a commutable distance and, thus, this agreement potentially creates frequent interchanges of students and faculty through the sustainability science programs.

2. The IR3S is attempting to establish a joint educational program. For this program to be effective, we are 
designing a joint sustainability core course, frontier for sustainability science, to be offered in March 2009, as a required course for the joint educational program. This course consists of lectures and discussions conducted by leading scholars in sustainability science from the five universities.

3. The IR3S makes use of the opportunities afforded by the existing international connections. For example, the University of Tokyo and the Asia Institute of Technology organize the Intensive Program for Sustainability (IPoS) annually. The participants are students from the universities in the Southeast Asia region, the US, and Europe, as well as the IR3S universities. In addition, faculty members from the IR3S universities also participate in the program, which can be thought of as faculty development.

While we continue to improve the program at Osaka University, these networks will help nurture students who play an active role in the field of sustainability.

Acknowledgments We thank Akiko Baba and Yoshito Kita for their research assistance. We also acknowledge the financial support by the Ministry of Education, Culture, Sports, Science and Technology (MEXT) of Japan through Special Coordination Funds for Promoting Science and Technology, as part of the flagship project, "Sustainability Science Education" in the IR3S.

\section{References}

Banas S (2007) A survey of university-based sustainability science programs. Supplement for the Forum for Sustainability Science Programs Roundtable AAAS 2007 Annual Meeting
Calder W, Clugston RM (2003) Progress toward sustainability in higher education. Environmental law reporter 33, Environmental Law Institute, Washington, pp 1003-1023

Copernicus Campus Sustainability Center (2006) Copernicus guidelines for sustainable development in the European higher education area: how to incorporate the principles of sustainable development into the Bologna process. Copernicus Campus, Oldenburg, Germany

Government of Japan (2007) Becoming a leading environmental nation in the 21st century: Japan's strategy for a sustainable society. Government of Japan: cabinet meeting decision

Komiyama H, Takeuchi K (2006) Sustainability science: building a new discipline. Sustain Sci 1(1):1-6

Lattuca LR (2001) Creating interdisciplinary. Vanderbilt University Press, Nashville

Martens P (2007) Problem-based learning. Maastricht University, Mimeo

Morioka T, Saito O, Yabar H (2006) The pathway to a sustainable industrial society: initiative of the Research Institute for Sustainability Science (RISS) at Osaka University. Sustain Sci $1(1): 65-82$

Stibbe A (2008) Words and worlds: new directions for sustainability literacy. Lang Ecol 2:1-11

UNCED (1992) Agenda 21, the United Nations programme of action from Rio. UN Department of Public Information, New York

UNU-IAS (2005) Mobilizing for education for sustainable development: towards a global learning space based on regional centres of expertise. United Nations University, Institute of Advanced Studies, Yokohama, Japan

Wright TSA (2004) The evolution of environmental sustainability declarations in higher education. In: Corcoran BP, Wals AEJ (eds) Higher education and the challenge of sustainabilityproblems, promise, and practice. Kluwer Academic Publishers, Dordrecht, pp 7-19 